\title{
ANALISIS DAN PEMBUATAN TEKNIK RIGGING ANIMASI 3D TENDANGAN DWI CHAGI (BACK KICK) PADA MODEL PELATIHAN TAEKWONDO
}

\author{
Agustian Dwi Sambodo $^{1)}$, Didit Suhartono ${ }^{2)}$, Agung Prasetyo ${ }^{3)}$ \\ 1) 2) 3) Teknik Informatika Universitas Amikom Purwokerto \\ email : agustiandwis@gmail.com ${ }^{l)}$,didit@amikompurwokerto.ac.id ${ }^{2)}$ pras@amikompurwokerto.ac.id ${ }^{3)}$
}

\begin{abstract}
Abstraksi
Analisis dan Pembuatan Teknik Rigging Animasi 3D Tendangan Dwi Chagi pada Model Pelatihan Taekwondo, penelitian ini bertujuan membuat video animasi 3D untuk memperagakan gerakan tendangan Dwi Chagi pada model pelatihan Taekwond sebagai media pembelajaran dan edukasi di masa pandemi di UKM Taekwondo Universitas Amikom Purwokerto. Pembuatan animasi 3D ini berfokus pada teknik rigging untuk penerapannya tentang tendangan Dwi Chagi berupa video animasi 3D. Rigid body yang ideal memiliki aturan yang jelas dan terdefinisi pada sebuah objek bergerak di bawah aksi kekuatan dan momen, serta bagaimana batasan ideal seperti bergulir dengan sempurna, bergeser, dalam sistem pergerakan sebuah objek. Metode yang digunakan adalah Kualitatif, penelitian ini dimulai dengan tahapan yang runtut seperti pra-production, production dan pascaproduction. Hasil penelitian ini membuat animasi 3D sebagai media pembelajaran dan informasi tentang bagaimana teknik tahapan melakukan tendangan dwi chagi pada beladiri taekwondo menggunakan teknik rigging berformat MP4 yang sudah di uji dengan metode Blackbox.
\end{abstract}

\section{Kata Kunci :}

Animasi, 3D, Rigging, Taekwondo, Dwi Chagi

\begin{abstract}
Analysis and Making of Dwi Chagi's 3D Kick Animation Rigging Technique on the Taekwondo Training Model, this study aims to create a 3D animated video to demonstrate Dwi Chagi's kick motion in the Taekwond training model as a medium of learning and education during the pandemic at Taekwondo UKM, Amikom University, Purwokerto. This $3 D$ animation development focuses on rigging techniques for its application of Dwi Chagi's kick in the form of a 3D animation video. The ideal rigid body has clear and defined rules on an object moving under the action of forces and moments, as well as how ideal boundaries such as scrolling perfectly, shift, in the system of movement of an object. The method used is qualitative, this research begins with coherent stages such as pre-production, production and post-production. The results of this study make $3 D$ animation as a learning medium and information about the technique of the stages of doing a dwi chagi kick in taekwondo using the mp 4 format rigging technique that has been tested using the Blackbox method.
\end{abstract}

Keywords :

Animation, 3D, Rigging, Taekwondo, Dwi Chagi

\section{Pendahuluan}

Produk-produk digital kreatif semakin berkembang seiring dengan pesatnya perkembangan teknologi saat ini. Banyak produk game, animasi, template digital maupun media informatif baru yang bermunculan. Salah satu produk digital kreatif yang memiliki banyak manfaat dalam penyampaian informasi dan simulasi adalah media informatif. Media informatif dapat dipadukan dengan semua elemen multimedia untuk menghasilkan sebuah karya teknologi yang memberikan stimulan kepada penggunanya. Beberapa penelitian sebelumnya juga menggunakan teknik rigging sebagai media informatif untuk pembelajaran seperti penelitian yang dilakukan oleh Muhammad Lutfi Al Ayubi dan Mirza Nur Hidayat dengan judul penelitian Analisis Kebutuhan Pengembangan Media Pembelajaran Berbasis Animasi 3D Menggunakan Teknik Rigging, pada penelitiannya membahas teknik rigging sebagai media pembelajaran pada mata pelajaran fisika dengan tujuan untuk mengetahui respon peserta didik terhadap rancangan pengembangan media pembelajaran berbasis animasi 3D menggunakan teknik rigging [1]. Penelitian lain juga dilakukan oleh Sofyan pada 2018 meneliti implementasi Rigid Body Pada Rigging Terhadap Animasi Dinamis Model Kendaraan Tiga Dimensi dengan tujuan untuk mempromosikan Metode penelitian yang digunakan adalah eksperimental yang mempunyai empat prinsip dasar yaitu replication, randomization, blocking, validation. Tujuan penelitian ini untuk memberikan pengetahuan mengenai model kendaraan dengan model 3D.[2]

Dari beberapa penelitian sebelumnya mengenai teknik rigging maa penulis melakukan wawancara dengan UKM Pelatihan Taekwondo Universitas Amikom Purwokerto mengenai pembelajaran yang sejauh ini telah dilaksanakan. Dari wawancara yang 
telah dilakukan para mahasiswa yang mengikuti UKM Taekwondo masih mengalami kesulitan dalam memahami berbagai gerakan yang ada di Taekwondo diantara gerakan yang sulit yaitu gerakan tendangan. Dari banyaknya variasi tendangan penulis mengambil satu gerakan tendangan $d w i$ chagi untuk penelitiannya, karena gerakan ini dibutuhkan latihan berulang - ulang agar bisa dipraktekan dengan benar. Namun selama hampir 8 bulan para anggota Taekwondo tidak latihan karena terkendala social distancing dan keadaan yg tidak memungkinkan untuk latihan secara langsung seperti biasanya dikarenakan wabah pandemi corona . Apalagi di musim pandemi seperti tahun 2020 sekarang ini, dimana perkuliahan dan semua aktifitas belajar mengajar, aktifitas ekstrakulikuler dan kegiatan mahasiswa dilakukan di rumah. Tentu ini menjadi hambatan para mahasiswa yang mengikuti pelatihan Taekwondo. Sehingga perlu adanya media yang dapat membantu pembelajaran kegiatan menirukan gerakan Taekwondo khususnya tendangan $d$ wi chagi ( Back Kick).

\section{Tinjauan Pustaka}

a. Analisis

Kegiatan pencarian suatu pola disebut Analisis. Analisis data merupakan proses pencarian dan penyusunan informasi secara sistematis berdasarkan data yang dihasilkan melalui proses wawancara, catatan lapangan, dan dokumentasi. Analisis data dilakukan dengan cara mengorganisasikan data ke dalam kategori, menjabarkan data, melakukan sintesa data, menyusun data ke dalam pola, memilih mana yang penting dan yang akan dipelajari, dan terakhir membuat kesimpulan sehingga mudah difahami oleh diri sendiri maupun orang lain.[3]

b. Multimedia

Multimedia adalah suatu kombinasi teks, seni, suara, gambar, animasi, dan video yang disampaikan secara interaktif.[4]

c. Teknik Rigging

Rigging adalah proses atau teknik yang digunakan dalam komputer grafis sebagai penghubung antara modeling dan animasi. Pada Teknik rigging, terdapat proses modeling dimana serangkaian alat digunakan untuk membangun objek animasi yang bertujuan untuk memanipulasi geometri virtual menjadi bentuk tertentu. Selanjutnya, tahap rigging dilakukan dan dihubungkan dengan objek geometri. Unsurunsur ini yang memungkinkan animator untuk memanipulasi atau menyerupai bentuk dan posisi objek geometri [2]

d. Animasi

Animasi merupakan perubahan visual sepanjang waktu yang memberi kekuatan. [5]

e. Taekwondo
Taekwondo adalah seni bela diri, atau metode pertempuran antarbangsa yang digunakan untuk membela diri. Taekwondo dimulai di Korea. Dalam bahasa Korea, kata "Taekwondo" berarti seni menendang dan meninju.

f. Tendangan Dwi Chagi

Dwi Chagi adalah salah satu teknik tendangan pada Taekwondo yang yang cukup sulit dilakukan. Tendangan ini sering dilakukan oleh para Altet Taekwondo dikarenakan kekuatan tendangan yang dihasilkan sangat besar. Putaran awal yang dilakukan sebelum melakukan tendangan menyebabkan kekuatan tendangan ini menjadi besar. Tendangan ini dilakukan dengan lebih dulu memutar tubuh 360 derajat untuk menghadapi lawan yang berada di depan.[6]

\section{Metode Penelitian}

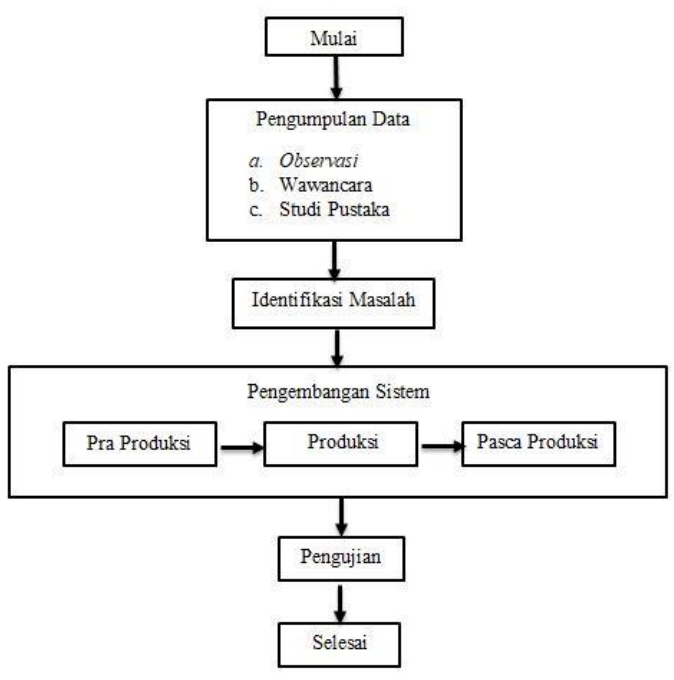

Gambar 1. Diagram Alur Penelitian

Metode pengumpulan data dan pengembangan sistem pada penelitian ini adalah:

a. Teknik Pengamatan (Observation)

Observasi merupakan teknik pengumpulan data yang mempunyai ciri yang spesifik dibandingkan dengan teknik lain seperti wawancara dan kuesioner. Jika wawancara selalu berkomunikasi dengan orang maka observasi tidak terbatas pada orang tetapi objek - objek yang lain. [3]

b. Wawancara

Jika peneliti ingin mengadakan studi pendahuluan untuk menemukan permasalahan yang harus diteliti maka wawancara merupakan teknik pengumpulan data yang tepat. Selain itu, wawancara juga digunakan jika peneliti ingin mengetahui hal-hal yang lebih mendalam dari responden dengan jumlah yang sedikit atau kecil.[3]

c. Metode Studi Pustaka

Pengumpulan data dengan melakukan studi pustaka mencakup buku-buku, teks, makalah, dan 
buku petunjuk teknis terpadu. Browsing internet juga termasuk dalam metode studi pustaka[7].

d. Dokumentasi

Dokumentasi adalah semua bahan pustaka, baik dalam bentuk tulisan, catatan, maupun dalam bentuk rekaman lainnya seperti pita suara atau cassette, video, tapes, film, filmstrip, slide, microfilm mucrofis, gambar dan foto [8].

e. Identifikasi Masalah

Mengidentifikasi masalah yang terdapat dalam masyarakat, kemudian observasi yaitu mendatangi suatu tempat atau sumber terkait masalah tersebut untuk mencari data atau sumber yang dapat dijadikan informasi tambahan.

f. Metode Pengembangan Sistem

Metode pengembangan sistem yang digunakan adalah metode pengembangan [9]. Dalam metode pengembangan sistem tersebut terdapat tiga tahapan yaitu : Pra-Produksi, Produksi, dan Paska- Produksi. Metode pengembangan sistem ini dipilih karena lebih terstruktur, mudah dalam mengaplikasikannya dan tahapan dalam pembuatannya lebih urut serta mudah dipahami.

g. Pengujian

Tahap pengujian dilakukan setelah menyelesaikan tahap rendering. Pada tahap ini dilakukan pengujian terhadap teknik rigging yang digunakan apakah gerakan yang di buat sudah sesuai dengan yang di harapkan menggunakan blackbox testing.

\section{Hasil dan Pembahasan \\ Analisis Hasil}

Hasil yang dibuat adalah video animasi yang dapat ditayangkan maupun disebarkan melalui media televisi, video CD/DVD, serta media sosial youtube maupun melalui internet, yang dimana masyarakat dapat melihat dan tertarik dengan beladiri taekwondo. Untuk tahapannya akan dijelaskan sebagai berikut.

1. Tahap Pra Produksi

Tahapan berikut adalah pembuatan secara keseluruhan untuk dipesiapkan sebagai penciptaan animasi video meliputi ide cerita, tema cerita, skenario, sketsa, storyboard, take voice and music backsound.

2. Tahap Produksi

Merupakan tahap dimana pembuatan video animasi "implementasi teknik rigging pada video animasi 3D sebagai informasi atau edukasi tata cara melakukan gerkan tendangn $d w i$ chagi (back kick) yang baik" dibuat. Berikut merupakan tahapan dalam proses produksi yang dilalukan adalah sebagai berikut:

\section{a. Modelings}

Pada proses ini objek dan enviroment. Software ini digunakan karena membuat modelling menjadi lebih mudah dan hasil animasi yang dibuat menjadi cukup bagus. Modeling Karakter Pada gambar 4.2 dibawah adalah hasil pembentukan karakter yang di awali pembuatan menggunakan box. Pembentukan karakter menggunakan lowpoly.

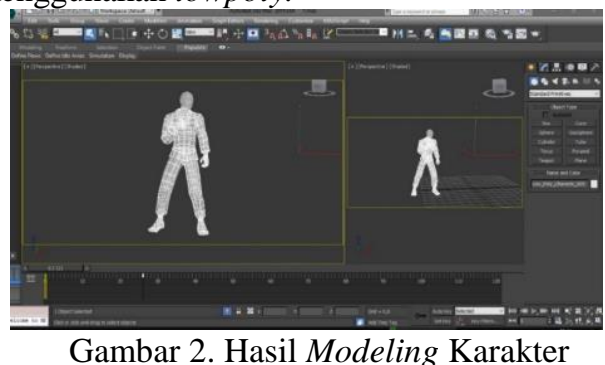

\section{b. Texturings}

Pada tahapan ini yaotu memebrikan material dan warna unutk sebuah objek animasi 3D yang telah dibuat, material bisa didapatkan sperti berupa gambar maupun foto berformat jpeg dengan aplikasi seperti Adobe Photoshop, GIMP dan lain sebagainya. Pada proses texturing ini karakter diberi warna merah untuk baju, putih untuk celana, dan sepatu berwarna hitam.

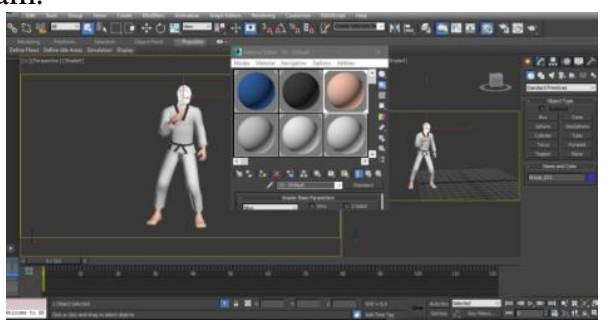

Gambar 3. Texturing Karakter

c. Rigging

Pada langkah ini merupakan proses dimana objek 3 dimensi dilakukan penambahan tulang atau rigging karakter sehingga objek 3 dimensi yang telah dibuat dapat dilakukan proses animasi.

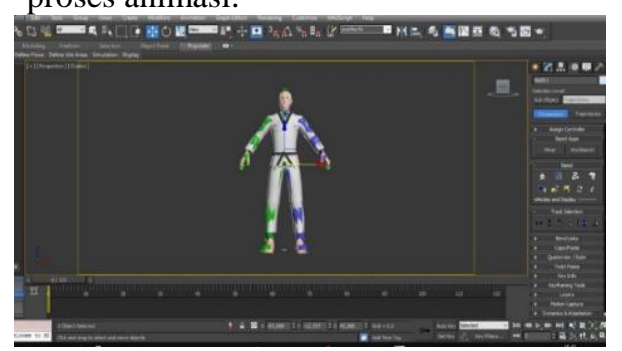

Gambar 4. Penambahan Biped Dalam Proses Rigging

d. Lighting

Mengunakan pencahayaan Target Spot yang dapat dijumpai pada menu Standard. Dan menambahkan pencahayaan Omni, yang terdapat pada menu Standard. 


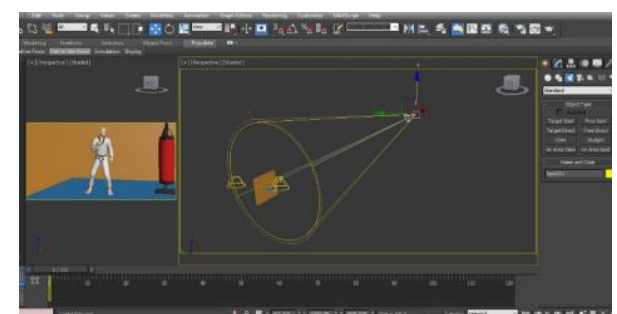

Gambar 5. Proses Pemberian Cahaya

(Lighting)

e. Environment effects

Pada software Autodesk 3ds Max 2014 terdapat cara mengganti environment (background) yaitu dengan mengklik menu Render lalu pilih Environment. Maka akan muncul jendela Environment and Effect.

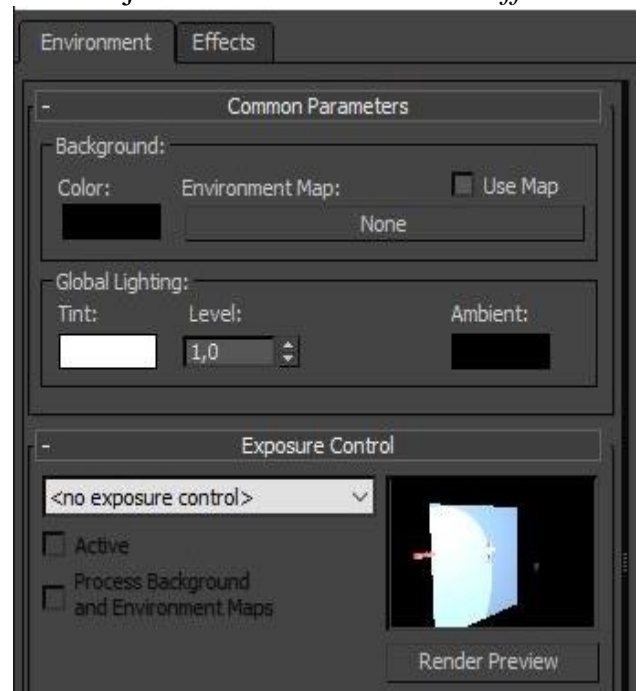

Gambar 6. Jendela Environment And Efect pada Software Autodesk 3Ds Max

\section{f. Animations}

Proses ini dilakukan setelah model sudah diberi 'tulang' atau sering disebut bone (proses rigging).

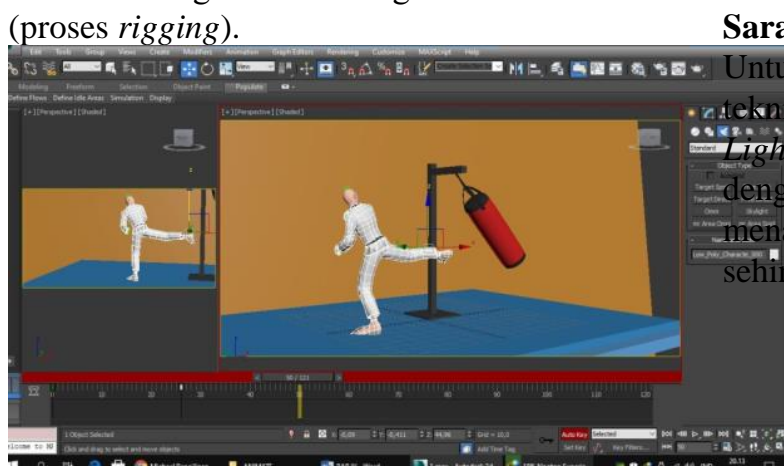

Gambar 7. Proses Animation

\section{g. Renderings}

Pada tahapan ini melakukan pembuatan model yang dibuat yang didalamnya memuat geometry, texture, environment, lighting, dan animation. Tahapan ini dapat membuat tampilan bagus dari kahir penciptaan animasi 3D.
Merupakan tahap akhir menyatukan yang sudah dikerjakan dalam proses produksi video animasi "Video Animasi Pembelajaran gerakan Dwi Chagi (Back Kick)" Berikut merupakan tahapan dalam proses pasca produksi meliputi editings, Addings sound and audios, dan Final Rendering.

\section{Pengujian}

Pada tahap pengujian, peneliti menggunakan pengujian dengan blackbox testing. Black box testing adalah metode pengujian perangkat lunak yang tes fungsionalitas dari aplikasi yang bertentangan dengan struktur internal. Pengetahuan khusus dari kode aplikasi ataua struktur internal dan pengetahuan pemrograman pada umumnya tidak diperlukan. Uji kasus dibangun disekitar spesifikasi, persyaratan, dan desain untuk menurunkan uji kasus. Tes ini dapat menjadi fungsional dan non fungsional, meskipun biasanya fungsional. Perancang uji memilih input yang valid dan tidak valid dan menemukan output yang benar.

\section{Kesimpulan dan Saran \\ Kesimpulan}

Dari hasil pengujian dengan metode blackbox berhasil menerapkan teknik rigging pada animasi $3 D$ tendangan back kick (dwi chagi).Telah berhasil dibuat media pembelajaran tentang gerakan tendangan Dwi Chagi (back kick) mengunakan video Animasi 3D dengan menerapkan teknik rigging serta menampilkan narasi dan visual animasi 3D pada UKM Taekwondo Universitas Amikom berdurasi 03 menit 00 detik yang berformat $m p 4$. Video animasi 3D ini dapat digunakan agar peserta UKM Taekwondo Universitas Amikom Purwokerto lebih mudah memahami cabang dari gerakan Taekwondo yaitu tendangan $d w i$ chagi (back kick) secara mandiri.

\section{Saran}

$\mathrm{k}$ penelitian selanjutnya bisa melakukan analisis $\mathrm{k}$ yang lain, seperti analisis teknik Texuring, ting, Rotoscoping. Pembuatan animasi 3D an teknik rigging dan tema yang sama bisa ambahkan tendangan yang ada di Taekwondo ngga lebih bervariasi.

\section{Tahap Pasca Produksi}




\section{Daftar Pustaka}

[1] M. Lutfi, A. Ayubi, dan M. N. Hidayat, "Analisis Kebutuhan Pengembangan Media Pembelajaran Berbasis Animasi 3D Menggunakan Teknik Rigging," vol. 2, no. 1, hlm. 1-5, 2020.

[2] M. Ariyanto, S., Utami, E., dan Sofyan, A., "Implementasi Rigid Body Pada Rigging Terhadap Animasi Dinamis Model Kendaraan Tiga Dimensi," Angkasa J. Ilm. Bid. Teknol., vol. 10, no. 1, hlm. 77, 2018,

[3] Sugiyono, Metode Penelitian Bisnis. Bandung: Alfabeta, 2018.

[4] I. D. Kurniawati dan S. Nita, "Media Pembelajaran Berbasis Multimedia Interaktif Untuk Meningkatkan Pemahaman Konsep Mahasiswa," DoubleClick J. Comput. Inf. Technol., vol. 1, no. 2, hlm. 68, 2018.

[5] S. Ariyati dan T. Misriati, "Perancangan Animasi Interaktif Pembelajaran Asmaul Husna," J. Tek. Komput. Amik Bsi, vol. II, no. 1, hlm. 116-121, 2016.

[6] V. Y. Suryadi, Taekwondo Poomse Taegeuk. Jakarta: PT. Gramedia Pusaka Utama, 2003.

[7] M. B. Rahmad dan T. Setiady, "Perancangan Sistem Informasi Inventory Sparepart Elektronik Berbasis Web PHP," J. Sarj. Tek. Inform., vol. 2, no. 2, hlm. 10, 2014.

[8] A. Nugrohoadhi, "Pengorganisasian Dokumen dalam Kegiatan Kepustakawanan," Khizanah al-Hikmah J. Ilmu Perpustakaan, Informasi, dan Kearsipan, vol. 3, no. 1, hlm. 1-10, 2015.

[9] M. Suyanto dan A. Yuniawan, Merancang Film Kartun Kelas Dunia. Yogyakarta: Andi Offset, 2006. 